\section{THE NORMAL WEIGHT OF DEXTROSE. ${ }^{1}$}

\author{
By C. A. BROWNE.
}

Received August 1, 1910.

There is perhaps no single constant given in the literature upon sugar analysis which shows such a variation in value as that given for the normal weight of dextrose. The range extends from 32.5 to nearly 33 grams. Landolt ${ }^{2}$ gives as the normal weight of dextrose for true cc. 32.65 grams and for Mohr cc. 32. 73 grams; Sidersky, ${ }^{3}$ in his latest work, gives the figures 32.82 grams for true cc. and 32.765 for Mohr cc.; Tucker ${ }^{4}$ and König 5 each give the value 32.68 grams, and this figure is the most common perhaps of any value given in the literature.

The reason for the considerable variation given to this constant is due largely to the fact that each authority has taken a different specific rotation of dextrose as a basis of calculation. There is no other sugar which shows such a difference in specific rotation for variations in concentration as dextrose; the values for specific rotation of dextrose, according to the formula of Tollens, $[\alpha]_{D}^{20}=5^{2.50}+0.018796 p+$ $0.0005 \mathrm{I} 683 p^{2}$, range from $5^{2.52}$ for a I per cent. solution to 54.73 for a 50 per cent. solution, which is about the limit of saturation at $20^{\circ} \mathrm{C}$.

Landolt ${ }^{1}$ gives as the normal weight of dextrose for a 5 per cent. solution 32.9 I grams, for a 15 per cent. solution 32.75 grams, and for a 25 per cent. solution 32.50 grams, in which connection he states that in weighing out the dextrose-containing material for polarization, the chemist must select his normal weight according to the amount of dextrose present. This of course involves a preliminary assay of the material under examination, which means practically doubling the work of analysis.

In the case of dextrose, as of all sugars, the author believes that one fixed value should be given to the normal weight, the value to be selected (as in the case of sucrose) being that weight of c. p. sugar which dissolved to Ioo true cc. and polarized at $20^{\circ} \mathrm{C}$. in a $200 \mathrm{~mm}$. tube will give a constant reading of exactly too upon the saccharimeter. If in the use of such a normal weight with impure products readings of less than roo are obtained, the latter are corrected by a table giving the true percentage equivalent of each division of the saccharimeter scale. The principle is the same as that employed in the well-known table of Schmitz for sucrose.

The author has converted the formula of Tollens for the specific rotation of dextrose from a percentage to a concentration basis, the latter form being more easily applied in the calculation of normal weights.

1 Paper read before the San Francisco meeting of the Amer. Chem. Soc., July, 1910.

2 Landolt, "Das Optische Drehungsvermögen" (1898), p. 448.

3 Sidersky, "Polarization et Saccharimetrie" (1908), p. 100.

4 Manual of Sugar Analysis (1905), p. 292. p. 216.

5 König, "Untersuchung landwirtsch. u. gewerb. wichtig. Stoffe,"
The formula is thus recalculated as $[\alpha]_{\mathrm{D}}^{20}=52.50+$ $0.0227 c+0.00022 c^{2}$. According to this formula the specific rotation of a dextrose solution containing 32.5 grams to $100 \mathrm{cc}$. (the preliminary value taken for the normal weight) is 53.47 . Calling the specific rotation of sucrose 66.5 and its normal weight, as under the present metric cc. standard, 26.00 grams, we obtain by means of the proportion $53.47: 66.5:$ : $26: x$, a value of 32.336 grams as the amount of c. p. dextrose necessary to dissolve to roo true cc. in order to obtain a constant reading of Ioo upon a saccharimeter standardized according to the requirements of the modern Ventzke scale.

The value just calculated is not absolutely correct, however, since it is based upon the assumption that the equivalent of $I^{\circ}$ Ventzke upon the circular scale is the same for dextrose as for sucrose. That there is a slight difference in the rotation dispersion of these two sugars as compared with quartz has long been recognized. According to Landolt, the value of $\mathrm{I}^{\circ}$ Ventzke in circular degrees for dextrose is 0.3448 . Brown, Morris and Miller give for a Io per cent. solution of dextrose the value $0.344^{2}$ and for a 5 per cent. solution the value $0: 3454$, the mean figure being 0.3448 , the same as that of Landolt. The value of the $100^{\circ}$ point of the Ventzke scale for dextrose may be taken, therefore, as 34.48 circular degrees. The specific rotation of a dextrose solution of 32.34 grams concentration (the value for the normal weight just calculated), according to the preceding formula, is 53.46 . Substituting these values in the general concentration formula for specific rotation $[\alpha]_{D}^{20}=$ $\frac{\alpha . \text { IOO }}{l . c}$ in which $\alpha$ is the reading in circular degrees, $l$ the $\mathrm{dcm}$. length of the observation tube, and $c$ the grams of sugar dissolved to roo cc.; we obtain for a $2 \mathrm{dcm}$. observation tube the value $c=\frac{34.48 \times 100}{2 \times 53.46}=$ 32.248 grams, or rounding off to the even hundredths of a gram, which can be done without a sensible error, 32.25 as the correct normal weight for dextrose.

The extent of the corrections necessary to be applied to the scale reading of a saccharimeter, when using the above normal weight, is shown by the following table, which gives the scale division, the cor-

\begin{tabular}{|c|c|c|c|c|}
\hline $\begin{array}{c}\text { Scale } \\
\text { division. }\end{array}$ & $\begin{array}{c}\text { Concentration. } \\
\text { Grams dex- } \\
\text { trose } 100 \\
\text { true cc. } \\
20^{\circ} \mathrm{C} .\end{array}$ & $\begin{array}{l}\text { Specific } \\
\text { rotation } \\
\text { dextrose }[\alpha]_{D}^{20 \circ}\end{array}$ & $\begin{array}{l}\text { Actual dex- } \\
\text { trose value } \\
\text { of scale } \\
\text { division. }\end{array}$ & $\begin{array}{l}\text { Correction } \\
\text { to be } \\
\text { added. }\end{array}$ \\
\hline 100 & 32.250 & 53.46 & 100.00 & 0.00 \\
\hline 90 & 29.025 & 53.34 & 90.20 & 0.20 \\
\hline 80 & 25.800 & 53.23 & 80.35 & 0.35 \\
\hline 70 & 22.575 & 53.12 & 70.45 & 0.45 \\
\hline 60 & 19.350 & 53.02 & 60.50 & 0.50 \\
\hline 50 & 16.125 & 52.92 & 50.51 & 0.51 \\
\hline 40 & 12.900 & 52.83 & 40.48 & 0.48 \\
\hline 30 & 9.675 & 52.74 & 30.41 & 0.41 \\
\hline 20 & 6.450 & 52.66 & 20.30 & 0.30 \\
\hline 10 & 3.225 & 52.58 & 10.17 & 0.17 \\
\hline 1 & 0.323 & 52.51 & 1.02 & 0.02 \\
\hline
\end{tabular}


responding percentage value of the normal weight, the specific rotation of dextrose corresponding to this weight of sugar in roo true cc. and the actual dextrose value of the scale division.

The correction necessary to be added to any reading $(s)$ of the saccharimeter scale, as formulated from the above table, is equal very closely to $+0.02 s-$ $0.002 s^{2}$. The percentage of dextrose (D) corresponding to any scale reading $(s)$ of the saccharimeter is therefore expressed by the formula

$$
\mathrm{D}=s+0.02 s-0.0002 s .^{2}
$$

The advantages of using a fixed value for the normal weight of dextrose as defined are very evident. The percentage of dextrose is found at one operation without the necessity of making a preliminary assay of the material in order to determine the exact quantity necessary to be weighed out. The method is also much more accurate than any of the processes using the variable normal weights prescribed in sugar literature.

The method described for dextrose is one which can be applied to all other sugars. By defining the normal weight for each of the sugars in the manner outlined in this paper, giving it a fixed value as in the case of sucrose, much of the confusion and inaccuracy attending the use of saccharimetric methods in sugar analysis can be avoided.

\section{MACHINE FOR MILLING SAMPLES OF WHEAT.}

By Geo. A. OLson.

Received October 1, 1910.

A milling outfit which will mill small samples of wheat (50 to 500 grams) as efficiently as the $\$ 550.00$ Allis-Chalmers experimental mill can be installed for a sum not exceeding \$10.00. With this outfit it is possible to test the milling qualities of flour, determine the various constituents contained therein, and determine the value of a wheat from a nutritive standpoint as well as the baking qualities.

This inexpensive outfit has been used by the writer in his research work and as a result has proven useful in a number of instances, among which may be mentioned, first, the modifying and remilling of flour; second, the germinating of wheat and its effect on the quality of the flour therefrom; third, determining the milling qualities of Washington wheats and new hybrids; fourth, determining the amount of flour contained in oats, barley, corn, etc.; fifth, the mixing of wheats to determine which combination of wheat makes the best blend for flour; sixth, assisting the State Grain Inspection Department in several instances; and seventh, determining the milling qualities of hybrid wheats from centgener plots. The possibilities for extending the use of this outfit in commercial, as well as experiment station, laboratories, flour mills, grain inspection departments, commission houses, and among the farmers seem promising from the many ways that it may be used satisfactorily.

In addition to the usefulness of this outfit in work similar to that done by the writer, it may also prove valuable in feeding-stuff work, $e$. g., for the detection of adulterations in ground feed, which are claimed to be made up of whole grains, when, as a matter of fact, oat hulls, corn cobs, etc., have been admixed. Such adulterations can readily be detected by making a milling determination. In cases of this kind flour determinations will tell more in regard to the nature of the feed than crude fiber determinations. By changing the bolting-cloths for sieves of any desired size, mechanical analysis of soil, the reduction of coal and ore can readily be accomplished.

In the following paragraphs a description of the mill, bolting machine, and the methods of operating the same, are given, together with results showing the efficiency of this inexpensive milling outfit.

Mill.-It is needless to state that the success of milling small samples of wheat depends as much upon the efficiency of the mill as it does upon the bolting machine. With the coöperation of the manufacturer of the mill used in this work, the writer finally succeeded in getting one of their standard mills modified in such a way that it will reduce wheat into flour as satisfactorily as if the wheat had passed between rollers. The mill has been thoroughly tested on both hard and soft wheats. It has been found, however, that it takes a little longer to reduce hard wheats than soft ones. In addition it requires some judgment to mill the same and different varieties of wheat. The mill (Laboratory Special) is manufactured by the Gray Iron Casting Co., Springfield, Ohio.

Bolting Machine.-The accompanying drawing shows the construction of the bolting machine used by us. The gearing from an old-style Babcock tester was used, leaving one of the arms on the horizontal wheel long enough so as to allow a three-inch reciprocal motion. Other forms of shaking devices will answer the same purpose. A modified soap box with a platform built about one-third the distance from the bottom to hold a removable drawer, beveled flanged pieces inside the box to permit the flour to drop toward the center of the drawer, and two strips of wood to hold the grooved sliding board (having an opening large enough to hold the bolting frames), which is connected by means of a shaft to the arm on the horizontal wheel, completes the machine. A tin box would be preferable to a wooden box owing to the fact that the smooth surface would tend to remove the danger of loss of flour in sifting and make it easier to collect same.

Bolting Frames.-The bolting frames were made out of crayon boxes with the bottoms sawed off. Besides a 20-mesh wire gauze, a No. $3^{\circ} \mathrm{GG}$, No. 50 